\title{
HIV Promotes NLRP3 Inflammasome Complex Activation in Murine HIV-Associated Nephropathy
}

Shabirul Haque, ${ }^{*}$ Xiqian Lan, ${ }^{*}$ Hongxiu Wen, ${ }^{*}$ Rivka Lederman, ${ }^{*}$ Amrita Chawla, ${ }^{*}$ Mohamed Attia, ${ }^{*}$ Ramchandra P. Bongu, ${ }^{*}$ Mohammad Husain, ${ }^{\dagger}$ Joanna Mikulak, ${ }^{\ddagger}$ Moin A. Saleem, ${ }^{\S}$ Waldemar Popik, ${ }^{\top}$ Ashwani Malhotra, ${ }^{*}$ Praveen N. Chander, ${ }^{\|}$and Pravin C. Singhal*

From the Renal Molecular Research Laboratory,* Feinstein Institute for Medical Research, Hofstra North Shore Long Island Jewish Medical School, New York, New York; the Jamia Millia Islamia,${ }^{\dagger}$ New Delhi, India; the Unit of Clinical and Experimental Immunology, ${ }^{\ddagger}$ Humanitas Clinical and Research Center, Rozzano, Milan, Italy; the Renal Academic Unit, ${ }^{\S}$ University of Bristol, Bristol, United Kingdom; the Center for AIDS Health Disparities Research, ${ }^{\natural}$ Meharry Medical College, Nashville, Tennessee; and the Department of Pathology, ${ }^{\prime}$ New York Medical College, Valhalla, New York

Accepted for publication October 20, 2015.

Address correspondence to Pravin C. Singhal, M.D., Division of Kidney Diseases and Hypertension, 100 Community Dr., Great Neck, NY 11021. E-mail: psinghal@ nshs.edu.

\begin{abstract}
Dysregulated growth and loss of podocytes are important features of HIV-associated nephropathy. Recently, HIV was reported to induce a new type of programed cell death, pyroptosis, in T lymphocytes through induction of Nod-like receptor protein 3 (NLRP3) inflammasome complexes. We evaluated the role of HIV in podocyte NLRP3 inflammasome formation both in vivo and in vitro. Renal cortical sections of HIV-transgenic mice (Tg26) displayed increased expression of NLRP3, ASC (a CARD protein), caspase-1, and IL-1 $\beta$ proteins, confirming NLRP3 inflammasome complex formation in podocytes of $\operatorname{Tg} 26$ mice. Renal tissues of $\operatorname{Tg} 26$ mice also displayed enhanced mRNA levels and protein expressions of inflammasome markers (NLRP3, ASC, and caspase-1, and IL-1 $\beta$ ). Serum of Tg26 mice also showed elevated concentrations of IL-1 $\beta$ cytokine compared with FVBN mice. HIV induced pyroptosis in a dose- and time-dependent manner within podocytes, a phenotype of inflammasome activation. Caspase- 1 inhibitor not only attenuated podocyte expression of caspase- 1 and IL-1 $1 \beta$ but also provided protection against pyroptosis, suggesting that HIV-induced podocyte injury was mediated by caspase-1 activation. Interestingly, HIV-induced podocyte pyroptosis could be partially inhibited by Tempol (a superoxide dismutase-mimetic agent) and by glyburide (an inhibitor of potassium efflux). These findings suggest that generation of reactive oxygen species and potassium efflux contribute to HIV-induced pyroptosis and NLRP3 inflammasome activation in podocytes. (Am J Pathol 2016, 186: 347-358; http://dx.doi.org/10.1016/j.ajpath.2015.10.002)
\end{abstract}

Podocytes are highly specialized cells that play a key role in the pathogenesis of focal segmental glomerulosclerosis and its variants, frequently encountered glomerular lesions in HIV-associated nephropathy (HIVAN). ${ }^{1}$ They are a critical component of the glomerular filtration barrier and constitute slit diaphragm to limit passage of plasma proteins into the urinary space. ${ }^{1}$ The absence of podocyte regeneration after cell injury is a major limitation in recovery from proteinuric kidney diseases. Accordingly, interventions that modulate the severity of podocyte injury offer a novel approach to preserve the integrity and permselectivity of the glomerular filtration barrier. On that account, varieties of therapeutic strategies are used to preserve the integrity of podocytes both in cellular and in animal models of kidney cell injuries. ${ }^{2}$
Pattern recognition receptors play a cardinal role in maintenance of pathogen-associated molecular patterns and damage-associated molecular patterns, responsive host innate system. ${ }^{3-7}$ Pathogen-associated molecular patterns use specific receptors, including Toll-like receptors, C-type lectin receptors, retinoic acid-inducible gene I-like receptors, and nucleotide oligomerization domain (Nod)-like receptors (NLRs). ${ }^{4-7}$ Several pathogens, including bacteria and viruses, were found to interact with NLRs and lead to the formation of NOD-like receptor protein (NLRP)-associated

Supported by NIH grants RO1DK 098074, RO1DK084910, RO1 DK083931 (P.C.S.), and R21 DK094735 (W.P.).

Disclosures: None declared. 
multiprotein complexes or inflammasomes. ${ }^{6,8-11}$ NLRP3 inflammasome complex is one of the most commonly formed inflammasomes in response to pathogen-associated/damageassociated molecular patterns. ${ }^{6}$ NLRPs act as the sensing components in these complexes. Encounter of a damageassociated molecular pattern or pathogen-associated molecular pattern signal by NLRP3s triggers the assembly of multicomponent protein platform, including NLRP, ASC (an apoptosis-associated speck-like protein containing CARD and PYD domains), and caspase-1 components. ${ }^{5,6}$ Although the cytokines such as IL-1 $\beta$ and IL-18 are usually transcribed via Toll-like receptor-NF- $\kappa \mathrm{B}$ signaling, they remain inert precursors and are activated by caspase- 1 , a component of the inflammasomes. ${ }^{11}$

Transforming growth factor (TGF)- $\beta$ was shown to play an important role in the development of kidney disease in general and HIVAN in particular. ${ }^{12-14}$ Patients with African American ancestry are prone to develop HIVAN.$^{15}$ Currently, this disparity was attributed to the presence of APOL1 variants in this population. ${ }^{16,17}$ However, the susceptibility to develop kidney disease in the past was attributed to higher amounts of circulating TGF- $\beta$ concentrations in this population. ${ }^{18}$ Because IL-1 $\beta$ was reported to stimulate kidney cell TGF- $\beta$ production, ${ }^{13}$ we speculate that HIV-induced activation of NLRs led to the formation of inflammasome complexes, which promoted generation of TGF- $\beta$ in HIVAN.

HIV-1 infection was reported to induce NLRP3 mRNA expression in monocyte-derived dendritic cells, ${ }^{19}$ and NLRP3 is associated with susceptibility to HIV-1 infection. ${ }^{20}$ Recently, inflammasome formation was reported to be the major contributor to HIV-induced cell death in T lymphocytes. ${ }^{21}$ Because HIV-induced podocyte death was reported to play an important role in the development and progression of HIVAN, ${ }^{22}$ we asked whether HIV is also promoting inflammasome formation in HIVAN.

In the present study, we observed that HIV-1 promoted IL-1 $\beta$ production and caspase-1 activation in kidney cells of HIVAN mice. In in vitro studies HIV enhanced protein expression of molecules that were involved in the formation of NLRP3 inflammasome complex and promoted IL-1 $\beta$ production. HIV promoted pyroptosis in podocytes which was inhibited by a caspase-1 inhibitor, an antioxidant (Tempol), and an inhibition of potassium efflux (NLRP3 inhibitor).

\section{Materials and Methods}

\section{Animal Strains (FVBN and Tg26 Mice)}

Age- and sex-matched FVBN (control) and HIV-transgenic (Tg26; on FVBN background) mice were used for this study. Breeding pairs of FVBN mice were obtained from The Jackson Laboratories (Bar Harbor, ME). Breeding pairs to develop Tg26 colonies were kindly gifted by Prof. Paul E. Klotman (Baylor College of Medicine, Houston, TX). The $\operatorname{Tg} 26$ transgenic animal carries the proviral transgene, pNL4-3:d1443, which encodes all of the HIV-1 genes except gag and pol; therefore, these mice are noninfectious. We are maintaining colonies of these mice in our animal facility. For genotyping, tail tips were clipped, DNA was isolated, and PCR studies were performed with the use of the following primers for Tg26: HIV-Forward, 5'-ACATGAGCAGTCAGTTCTGCCGCAGAC-3', and HIV-Reverse, 5'-CAAGGACTCTGATGCGCAGGTGTG- $3^{\prime}$. The Ethics Review Committee for Animal Experimentation of Long Island Jewish Medical Center approved the experimental protocol.

\section{Preparation of Human Podocytes}

Human podocytes (LY $8+13$ cell line) were obtained from Dr. Moin A. Saleem (University of Bristol, Southmead Hospital, Bristol, UK). Human podocytes were conditionally immortalized by introducing temperature-sensitive SV40-T antigen by transfection. ${ }^{23}$ In addition, the cells were transfected with a human telomerase construct. These cells proliferate at permissive temperature $\left(33^{\circ} \mathrm{C}\right)$ and enter growth arrest after transfer to the nonpermissive temperature $\left(37^{\circ} \mathrm{C}\right)$. The growth medium contained RPMI 1640, supplemented with $10 \%$ fetal bovine serum, $1 \times$ Pen-Strep, $1 \mathrm{mmol} / \mathrm{L}$ L-glutamine, and $1 \times$ Insulin, Transferrin, Selenium (Invitrogen; Carlsbad, CA) to promote expression of $\mathrm{T}$ antigen.

\section{Production of Pseudotyped Retroviral Supernatant Fluid}

Replication defective viral supernatant fluids were prepared as published previously. ${ }^{22}$ In brief, green fluorescent protein (GFP) reporter gene (from pEGFP-C1; Clontech, Palo Alto, CA) was substituted for $\mathrm{gag} / \mathrm{pol}$ genes in HIV-1 proviral construct pNL4-3. This parental construct (pNL4-3: $\Delta \mathrm{G} /$ P-GFP) was used to produce VSV.G-pseudotyped viruses to provide pleiotropism and high-titer virus stocks. Infectious viral supernatant fluids were produced by the transient transfection of 293T cells with the use of effectene (Qiagen Inc., Valencia, CA) according to the manufacturer's instructions. The HIV-1 gag/pol and VSV.G envelope genes were provided in trans with the use of pCMV R8.91 and pMD.G plasmids, respectively (gifts of Dr. Didier Trono, Salk Institute, La Jolla, CA). As a negative control, virus was also produced from pHR-CMV-IRES2-GFP- $\Delta$ B, which contained HIV-1 long terminal repeats and GFP expression vector $(\mathrm{V})$. The viral stocks were titrated by infecting HeLa tat cells with 10 -fold serial dilution as reported previously. ${ }^{22}$ The reciprocal of the lowest dilution showing expression of GFP was defined as GFP-expressing units per milliliter. Viral stocks that ranged from $10^{5}$ to $10^{6}$ GFP-expressing units $/ \mathrm{mL}$ were used.

\section{Morphologic Assay for Pyroptosis}

Pyroptosis is characterized by condensed nuclei and induction of pore formation in cytoplasmic membrane. ${ }^{24}$ To differentiate between types of cell death, we performed morphologic assay of control and experimental cells with the use of Hoechst 33342 to label nuclei in normal cells 
(normal fluorescence, blue) or apoptosed cells (bright fluorescence by fragmented and/or condensed nuclei) and propidium iodide (PI) to label nuclei (pink) in cells with large cytoplasmic pores (pyroptosis and necrosis). This double staining allowed us to identify normal cells (normal fluorescence by Hoechst-stained nuclei), apoptosed cells (bright fluorescence by Hoechst-stained condensed nuclei), pyroptosed cells (PI-stained condensed or fragmented pink nuclei), necrosed cells (swollen cells with PI-stained large pink nuclei). Hoechst and PI staining was performed for morphologic assay of cell death in control and experimental cells. In brief, after required treatments, culture medium was removed, and fresh medium that contained $10 \mu \mathrm{g} / \mathrm{mL}$ Hoechst 33342 was added for 10 minutes at $37^{\circ} \mathrm{C}$. Then, PI stain was added and kept on ice for 10 minutes. Images of the stained cells were captured immediately after staining with a Zeiss microscope (Carl Zeiss Micro-Imaging, Jena, Germany) equipped with a digital imaging system. Pyroptosed cells were counted in eight fields by two investigators unaware of the experimental conditions. Percentage of pyroptosed cells was calculated.

\section{Immunohistochemical Studies of Mice Kidney Tissues}

Renal cortical sections from FVBN (control) and Tg26 mice were de-paraffinized, and antigen retrieval was performed in a double boiler system. The endogenous peroxidase was blocked with $0.3 \%$ hydrogen peroxide in methanol for 30 minutes at room temperature. Sections were washed in phosphate-buffered saline (PBS) thrice and incubated in avidin and biotin blocking solution and then in blocking serum solution for 60 minutes at room temperature, followed by incubation with primary antibodies against either Cryopyrin/NLRP3 (sc-66846; Santa Cruz Biotechnology, Santa Cruz, CA), ASC (sc-22514-R; Santa Cruz Biotechnology), caspase-1 (sc-560360; Santa Cruz Biotechnology), or IL-1 $\beta$ (sc-7954; Santa Cruz Biotechnology) for overnight at $4^{\circ} \mathrm{C}$ in a moist chamber. Each of the sections were washed thrice with PBS and incubated with appropriate secondary antibody at 1:250 dilutions at room temperature for 1 hour. After washing with PBS three times, sections were incubated in $\mathrm{ABC}$ reagent (Vector Laboratories, Burlingame, CA) for one-half hour. Sections were washed thrice in PBS and then placed in Nova Red/hydrogen peroxide solution, counterstained with methyl green, dehydrated, and mounted with a xylene-based mounting media (Permount; Fisher Scientific Corporation, Fair Lawn, NJ). Appropriate positive and negative controls were used.

\section{Immunofluorescence of Mice Kidney Tissue}

Tissue slides of renal cortical sections from FVBN (control) and $\operatorname{Tg} 26$ mice were immersed in $100 \%$ xylene for 5 minutes four times, then placed in $100 \%$ ethanol for 5 minutes two times, and then into $70 \%$ ethanol 5 minutes two times, followed by $50 \%$ ethanol for 5 minutes twice. Slides were washed with double-distilled water for 1 minute. Now slides were subjected into $1 \times$ retrieve-All antigen unmasking system buffer (catalog no. SIG-31910-50; Covance, Dedham, MA) at $100^{\circ} \mathrm{C}$ for 90 minutes. Slides were kept at room temperature for 20 to 30 minutes for cooling and washed with $1 \times$ PBS. Slides were immersed in $0.3 \%$ Triton $\mathrm{X}-100$ for 20 minutes at room temperature. Slides were blocked with $2 \%$ bovine serum albumin for 2 hours. After blocking, primary antibody (caspase-1 at 1:25 dilution, IL-1 $\beta$ at 1:25 dilution, nephrin at 1:100 dilution) were added for overnight at $4^{\circ} \mathrm{C}$. Next day, slides were washed with $0.1 \%$ Triton X-100 for 5 minutes three times on shaker at room temperature. Secondary antibody was added with fluorescence conjugated at 1:500 dilution for 1 hour at room temperature. Slides were washed with $0.1 \%$ Triton X-100 for 5 minutes three times on shaker at room temperature and mounted for fluorescence microscopy.

\section{Protein Expression by Western Blot Analysis}

Renal tissues and cellular lysates were prepared in RIPA buffer [ $1 \times$ PBS, pH 7.4, $0.1 \%$ SDS, $1 \%$ NP-40, $0.5 \%$ sodium deoxycholate, $1.0 \mathrm{mmol} / \mathrm{L}$ sodium orthovanadate, $10 \mu \mathrm{L}$ of protease inhibitor cocktail (100 X; Calbiochem, Billerica, MA) per milliliter of buffer, and $100 \mu \mathrm{g} / \mathrm{mL}$ phenylmethylsulfonyl fluoride]. Protein was estimated by Bio-Rad (Hercules, CA) assay. Protein (20 $\mu \mathrm{g}$ to $30 \mu \mathrm{g})$ was electrophoresed on $10 \%$ to $15 \%$ SDS-PAGE. Electrophoresed proteins were transferred to an Immuno-blot polyvinylidene fluoride membrane (Bio-Rad). Membranes were blocked with PBS-Tween $(0.1 \%)$ with 5\% nonfat milk for 1 hour and incubated with primary antibodies overnight at $4^{\circ} \mathrm{C}$, followed by horseradish peroxidase-conjugated secondary antibodies (dilution 1:2000; Santa Cruz Biotechnology), and then immunoblots were developed with enhanced chemiluminescent solution (Pierce, Rockford, IL). Primary antibodies from Santa Cruz Biotechnology (sc), Cell Signaling (Danvers, MA), and Adipogen (Epalinges, Switzerland) were used at 1:1000 dilutions. Antibodies included caspase-1 (sc-56036), cleaved caspase-1 p20 antibody for human cell lysate [catalog no. 4199, rabbit monoclonal antibody; Cell Signaling], IL-1 $\beta$ (sc-7884; Santa Cruz Biotechnology), cleaved IL-1 $\beta$ (sc-23459; Santa Cruz Biotechnology), mature IL-1 $\beta$ [(3A6) mouse monoclonal antibody catalog no. 12242; Cell Signaling] for human and mouse cell lysates, ASC (sc-22514-R; Santa Cruz Biotechnology), cryopyrin/NLRP3 (catalog no. AG-20B-0014; Adipogen), caspase-1 p10 [(M-20) sc-514] for mouse cell lysate, actin (sc-1616; Santa Cruz Biotechnology), and $\beta$-actin (catalog no. 8H10D10 mouse monoclonal antibody; Cell Signaling). The blots were developed with a chemiluminescence detection kit (Pierce) and exposed to X-ray film (Eastman Kodak Co., Rochester, NY). Equal protein loading and the protein transfer were confirmed by immunoblotting of actin with the use of a polyclonal $\beta$-actin antibody (Santa Cruz Biotechnology) on the same Western blot analyses. 
RNA Extraction, cDNA Preparation, and quantitative real-time PCR (Taq-Man)

Total RNA was extracted from human podocytes or mouse kidney tissues with the use of Trizol reagent (Invitrogen) method. RNA was estimated by Epoch Biotek spectrophotometer. Approximately 4 to $5 \mu \mathrm{g}$ of total RNA was used for cDNA synthesis with the use of first-strand synthesis system (Invitrogen) by using random hexamer primers. Primers sequences, probe number, gene accession number from universal probe library are detailed in Table 1. Each sample was analyzed in duplicates with the use of cDNA as a template by using Eurogentec master mix. Fold change was calculated by comparing FVBN with Tg26 mice or control with experimental. Endogenous control for assay was $\beta$-actin gene. Data were analyzed with RQ manager version 1.2.1 (Applied Biosystems, Foster City, CA).

The data are expressed as relative mRNA expression with reference to control sample, normalized to an endogenous reference gene, $\beta$-actin.

\section{IL-1 $\beta$ Cytokine Measurement by Enzyme-Linked Immunosorbent Assay}

Serum concentrations of mature IL- $1 \beta$ cytokine in FVBN $(n=7)$ and $\operatorname{Tg} 26(n=7)$ mice were measured by enzymelinked immunosorbent assay with the use of mouse IL-1 $1 \beta /$ IL-1F2 quantikine enzyme-linked immunosorbent assay kit (catalog no. MLB00C; R\&D Systems, Minneapolis, MN) following protocols.

\section{Statistical Analysis}

To compare the mean values between two groups, the unpaired $t$-test was used. Statistical significance was defined as $P<0.05$. All results are shown as means \pm SD. Number of data points for each experiment is given in figure legends. At least three different sets of experiments were performed for each experimental condition. Data are presented as means $\pm \mathrm{SD}$.

\section{Results}

\section{In Vivo Studies}

Enhanced Expression of Inflammasome Complex Proteins in Renal Tissue and Podocytes of Tg26 Mice Compared with FVBN Controls

To determine the expression of NLRP3 inflammasome complex proteins in HIVAN, renal cortical sections of FVBN and Tg26 mice were immunolabeled for NLRP3, ASC, and IL-1 $\beta$. The representative immunohistochemistry images for NLRP3 expression in FVBN (Figure 1A) and Tg26 (Figure 1B) mice are shown. Cumulative data for $\mathrm{NLRP}^{+}$cells/glomerulus in both FVBN and $\mathrm{Tg} 26$ mice are shown in dot plot (Figure 1C). Tenfold higher number of glomerular cells displayed NLRP3 expression in $\mathrm{Tg} 26$ mice. Representative immunohistochemistry images for ASC expression in FVBN (Figure 1D) and Tg26 (Figure 1E) mice are shown. Cumulative outcome (dot plot) for $\mathrm{ASC}^{+}$ cells/glomerulus in both FVBN and Tg26 (Figure 1F) mice suggest that fourfold higher number of glomerular cells express ASC than FVBN. Representative immunohistochemistry images for IL-1 $\beta$ expression in FVBN (Figure 1G) and $\mathrm{Tg} 26$ (Figure $1 \mathrm{H}$ ) mice are shown. IL-1 $\beta$ positivity in glomerular cells of $\mathrm{Tg} 26$ mice are threefold to fourfold higher than FVBN (Figure 1I). Taken together, our data indicate that all three inflammasome protein markers (NLRP3, ASC, and IL-1 $\beta$ ) are up-regulated in podocytes of $\operatorname{Tg} 26$ mice.

Inflammasome protein expression in podocytes was further confirmed by immunofluorenscence double staining. Renal cortical sections of FVBN and Tg26 mice were stained with nephrin (podocyte marker in red color) and caspase-1 (green color). Both FVBN and Tg26 (Figure 1J) mice showed nephrin and caspase-1 staining. Merged images appeared orange/greenish orange. Image intensity of caspase-1 in glomeruli of FVBN and Tg26 mice was calculated by ImageJ software version 1.49 (NIH, Bethesda, MD; http://imagej.nih.gov/ij) and plotted (Figure 1K). Ratio of nephrin and caspase-1 was also calculated (Figure 1L). In both calculations (Figure 1, K and L), Tg26 mice expressed significantly higher caspase-1 in podocytes than FVBN mice.

Table 1 List of Mouse Primers

\begin{tabular}{|c|c|c|c|}
\hline Primer name & Accession no.* & Probe no. & Sequence \\
\hline Nlrp3 & NM_145827.3 & 82 & $\begin{array}{l}\text { Forward: } 5^{\prime}-\mathrm{CCCTTGGAGACACAGGACTC}-3^{\prime} \\
\text { Reverse: } 5^{\prime} \text {-GAGGCTGCAGTTGTCTAATTCC-3' }\end{array}$ \\
\hline ASC & AB059327.1 & 110 & $\begin{array}{l}\text { Forward: 5'-CCCTTGTTCGTCTACCCTCA-3' } \\
\text { Reverse: 5'-GGAACAGTTAAGCGCCAAAG-3' }\end{array}$ \\
\hline CASPASE-1 & NM_009807.2 & 103 & $\begin{array}{l}\text { Forward: } 5^{\prime} \text {-CCCACTGCTGATAGGGTGAC-3' } \\
\text { Reverse: } 5^{\prime} \text {-GCATAGGTACATAAGAATGAACTGGA-3' }\end{array}$ \\
\hline$\beta$-ACTIN & NM_007393.3 & 64 & $\begin{array}{l}\text { Forward: 5'-CTAAGGCCAACCGTGAAAAG-3' } \\
\text { Reverse: } 5^{\prime}-\mathrm{ACCAGAGGCATACAGGGACA}-3^{\prime}\end{array}$ \\
\hline
\end{tabular}

*Entrez Nucleotide, http://www.ncbi.nlm.nih.gov/nuccore. 

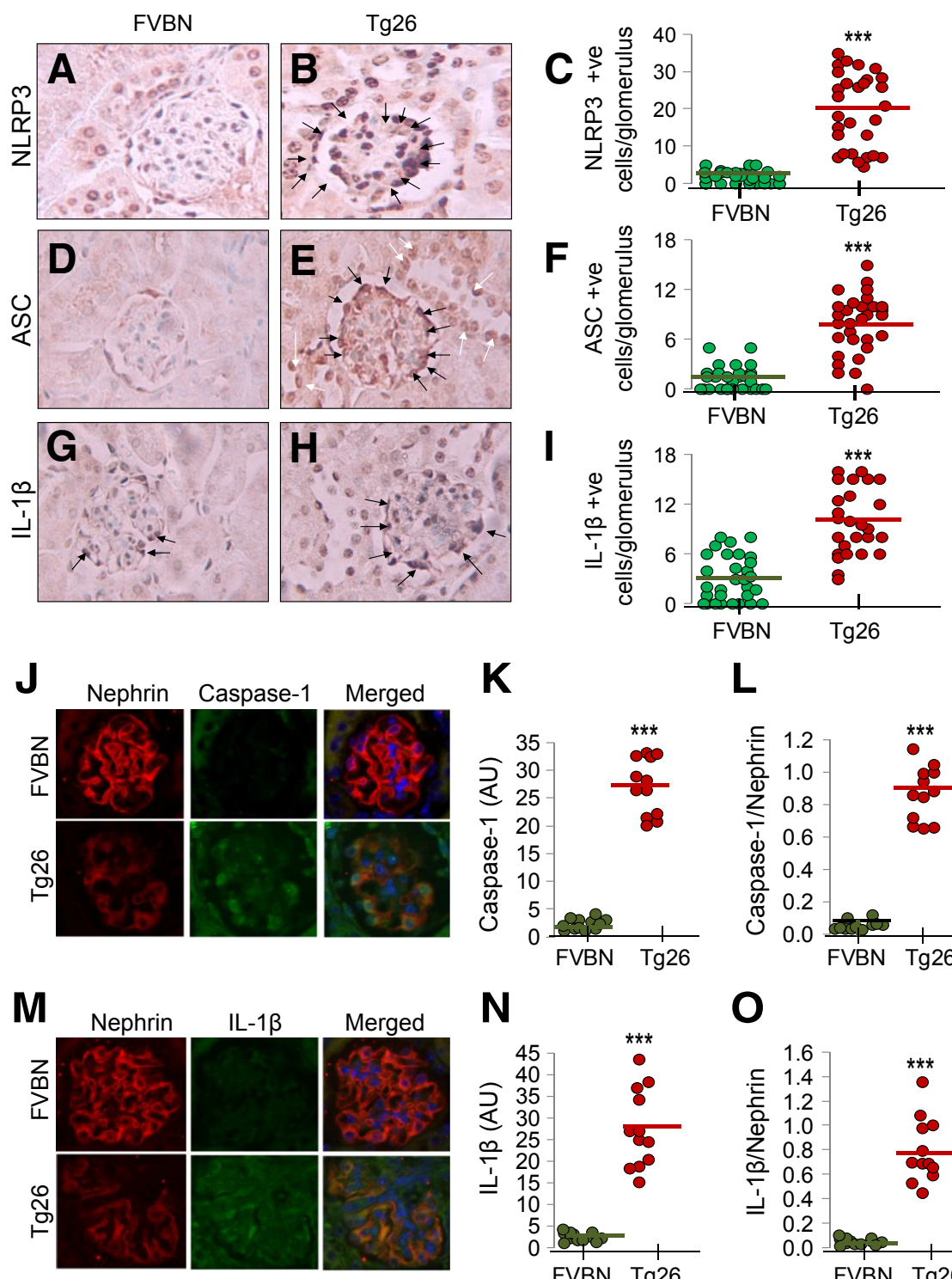

N

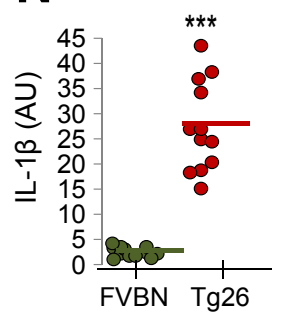

\section{(t)}

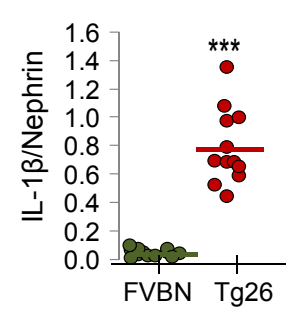

Figure 1 Podocytes display enhanced inflammasome complex protein (NLRP3, caspase-1, ASC, and IL-1 $\beta$ ) expression in HIVAN mouse model. $\mathbf{A}$ and B: Renal cortical sections were immunolabeled for NLRP3, ASC, and IL-1 $\beta$. Representative microimages are shown. Renal cortical sections in Tg26 mice display greater number of NLRP3labeled podocytes (B) than FVBN (A). C: Cumulative data are shown as dot plot. $\mathbf{D}$ and E: Renal cortical sections in Tg26 mice (E) show greater number of $\mathrm{ASC}^{+}$podocytes versus FVBN (D). F: Cumulative data are shown as dot plot. $\mathbf{G}$ and H: Similarly, renal cortical sections of $\mathrm{Tg} 26$ mice $(\mathbf{H})$ show higher number of IL- $1 \beta^{+}$cells than FVBN (G). Black arrows indicate IL1- $\beta^{+}$podocytes, and white arrows indicate IL1- $\beta^{+}$tubular cells. I: Cumulative data are shown as dot plots. Renal cortical sections of FVBN and Tg26 mice were stained with nephrin (podocyte marker in red and caspase-1 in green). J: Renal cortical sections of both FVBN and $\operatorname{Tg} 26$ were stained for nephrin and caspase- 1 . $\mathbf{K}$ and $\mathbf{L}$ : Merged images appear slight orange/greenish orange. Image intensity of caspase- 1 within FVBN and Tg26 was calculated by program ImageJ and plotted (K); data were also plotted in the form of ratios as dot plot (caspase-1/ nephrin, L). M: Both FVBN and Tg26 were stained for nephrin and IL-1 $\beta$. N and $\mathbf{0}$ : Merged images appear orangey/greenish orange. Image intensity of IL- $1 \beta$ within FVBN and Tg26 was calculated by program ImageJ and plotted $(\mathbf{N})$; data are also plotted in the form of ratios (nephrin/IL-1 $\beta$ ) as dot plot (0). Data are expressed as means (horizontal bar) \pm SD (scatter). $n=30$ glomeruli, 10 glomeruli from each mouse (C); $n=30$ glomeruli (F and $\mathbf{I}) .{ }^{* * *} P<0.001$ compared with respective FVBN. ASC, apoptosis-associated speck-like protein containing CARD and PYD domains; AU, arbitrary unit; HIVAN, HIVassociated nephropathy; NLRP, nucleotide oligomerization domain (Nod)-like receptor protein; Tg26, HIV-transgenic.
Next, IL-1 $\beta$ as an inflammasome substrate was evaluated in the podocytes. Both FVBN and Tg26 mice (Figure 1M) were stained with nephrin and IL-1 $\beta$. Merged images appeared orange/greenish orange. Image intensity of IL-1 $\beta$ within FVBN and $\mathrm{Tg} 26$ was calculated by ImageJ and plotted (Figure $1 \mathrm{~N}$ ); in addition, data were plotted in the form of ratios (IL-1 $\beta /$ nephrin) (Figure 1O). Dot plots (Figure 1, N and $\mathrm{O})$ show that IL- $1 \beta$ is significantly up-regulated in podocytes of Tg26 mice compared with FVBN mice. Taken together our data indicate that both caspase- 1 and IL- $1 \beta$ are abundantly expressed in podocytes of $\operatorname{Tg} 26$ mice.

\section{Podocyte mRNA Expression of Inflammasome Markers in} FVBN and Tg26 Mice

To determine transcription status of inflammasomes in the HIV milieu, NLRP3, caspase-1, ASC, and IL-1 $\beta$ mRNA expressions were evaluated in renal tissues of $\mathrm{Tg} 26$ and FVBN mice by quantitative real-time PCR. Total RNA was extracted from renal tissue of FVBN $(n=5-6)$ and Tg26 $(n=5-6)$ mice. RNA was converted into cDNA with the use of random hexamer primers. Quantified data are expressed in the form of fold-change, NLRP3 mRNA expression (Figure 2A), caspase-1 mRNA expression (Figure 2B), ASC mRNA expression (Figure $2 \mathrm{C}$ ), and IL-1 $\beta$ mRNA expression (Figure 2D) in FVBN and Tg26 mice (dot plots). Taken together, summarized data indicate that $\mathrm{Tg} 26$ mice express sixfold higher NLRP3 mRNA, fivefold higher caspase-1 mRNA, 4.5-fold higher ASC mRNA, and sevenfold higher IL-1 $\beta$ mRNA expression than FVBN mice.

Enhanced Expression of Inflammasome Complex Proteins (NLRP3, ASC, caspase-1, and IL-1 $\beta$ ) in Renal Tissues of Tg26 Mice

To evaluate inflammasome complex proteins in $\operatorname{Tg} 26$ and FVBN mice, cell lysates were prepared from FVBN $(n=7)$ and $\operatorname{Tg} 26(n=7)$ renal tissues. Equal amount of proteins 

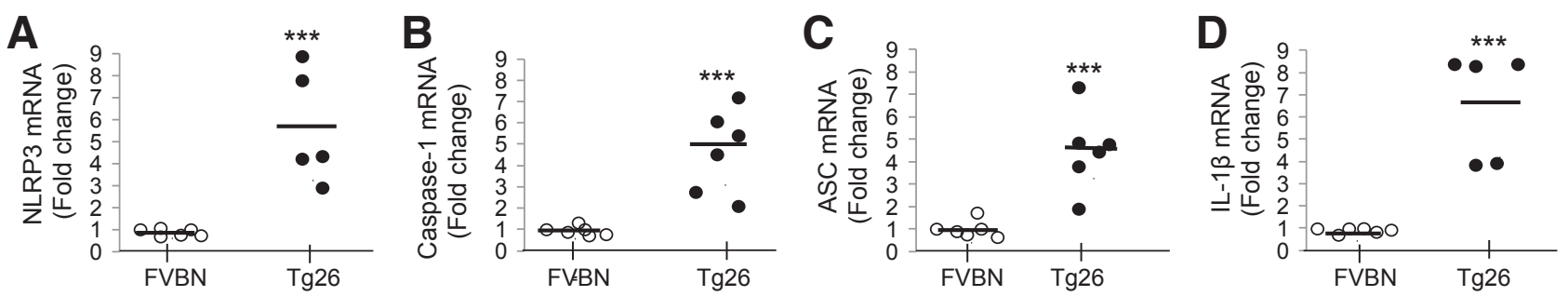

Figure 2 Tg26 mice display higher renal tissue mRNA expression of NLRP3, caspase-1, ASC, and IL-1 $\beta$. Total RNA was extracted from renal tissue of FVBN and Tg26 mice. A-D: RNA was converted into CDNA with the use of random hexamer primers. Fold-expression analysis of NLRP3 (A), caspase-1 (B), ASC (C), and IL-1 $\beta$ (D) mRNA expression were quantified by quantitative real-time PCR with the use of specific universal probe numbers and primers of each mRNA. Data are expressed as dot plots from each sample. Mean values are represented as horizontal bar. $n=6$ FVBN mice; $n=6$ Tg26 mice. ${ }^{* * *} P<0.001$ versus respective FVBN. ASC, apoptosis-associated speck-like protein containing CARD and PYD domains; NLRP, nucleotide oligomerization domain (Nod)-like receptor protein; Tg26, HIV-transgenic.

from different lysates were loaded onto gel for electrophoresis. Protein blots were probed with NLRP3, ASC, caspase1 , cleaved caspase-1 p10, IL-1 $331 \mathrm{kDa}$, and cleaved IL-1 $\beta$ $17 \mathrm{kDa}$. To quantify uniform loading, the same blots were reprobed for actin. Representative gels are shown in Figure 3A. Densitometric cumulative data $(n=7)$ indicate that NLRP3 expression is fivefold to sixfold higher in Tg26 mice than in FVBN mice (Figure 3B). ASC expression is fourfold to fivefold higher in $\mathrm{Tg} 26$ mice than in FVBN mice (Figure 3C). Caspase-1 expression is twofold to threefold higher in Tg26 mice (Figure 3D). Cleavage of caspase-1 p10 increased twofold in Tg26 mice compared with in FVBN mice (Figure 3E). IL-1 $\beta$ expression is sevenfold to eightfold higher in $\mathrm{Tg} 26$ mice than in FVBN mice (Figure 3F). Cleaved IL-1 $\beta(17 \mathrm{kDa})$ expression is sixfold to sevenfold higher in $\mathrm{Tg} 26$ mice than in FVBN mice (Figure 3G).

Serum IL- $1 \beta$ concentrations were determined by enzymelinked immunosorbent assay in FVBN $(n=7)$ and $\operatorname{Tg} 26$ $(n=7)$ mice. Data are shown as dot plot (Figure $3 \mathrm{H})$.
T26 mice showed sevenfold to eightfold higher serum concentrations of IL-1 $\beta(30-40 \mathrm{pg} / \mathrm{mL})$ than FVBN mice $(4-5 \mathrm{pg} / \mathrm{mL})$.

\section{In Vitro Studies}

To achieve HIV expression by podocytes we transduced podocytes either with vector (V, V/HPs) or NL43 (HIV/ HPs). In these instances, podocyte displayed overexpression of either $\mathrm{V}$ or HIV. To evaluate whether overexpression of $\mathrm{V}$ alters inflammasome expression, we compared expression of inflammasomes between control podocytes and V/HPs. Because overexpression of HIV in HIV/HPs is a limitation, we tried to circumvent this limitation by studying discrepancy in outcome of HIV infection in vivo versus in vitro studies. To compare data in vivo and in vitro studies, we transduced same HIV transgene (NL4-3) in podocytes which was used in the generation of $\operatorname{Tg} 26$ mice.
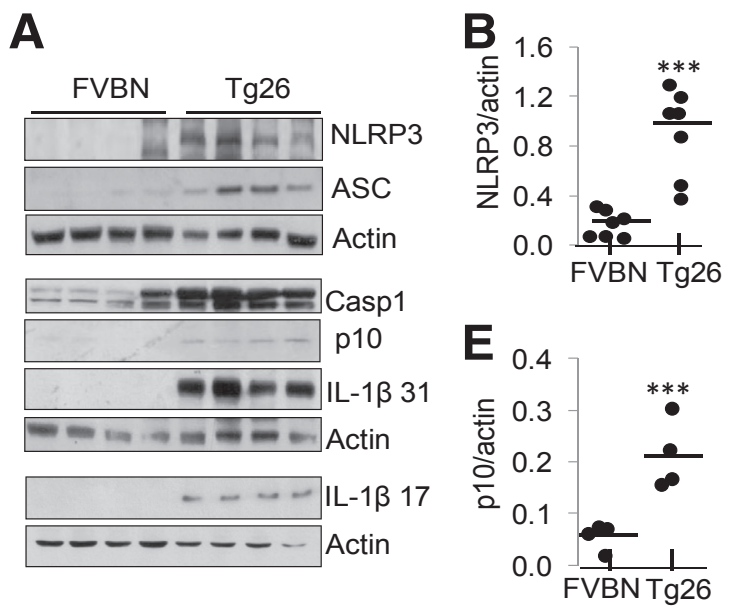
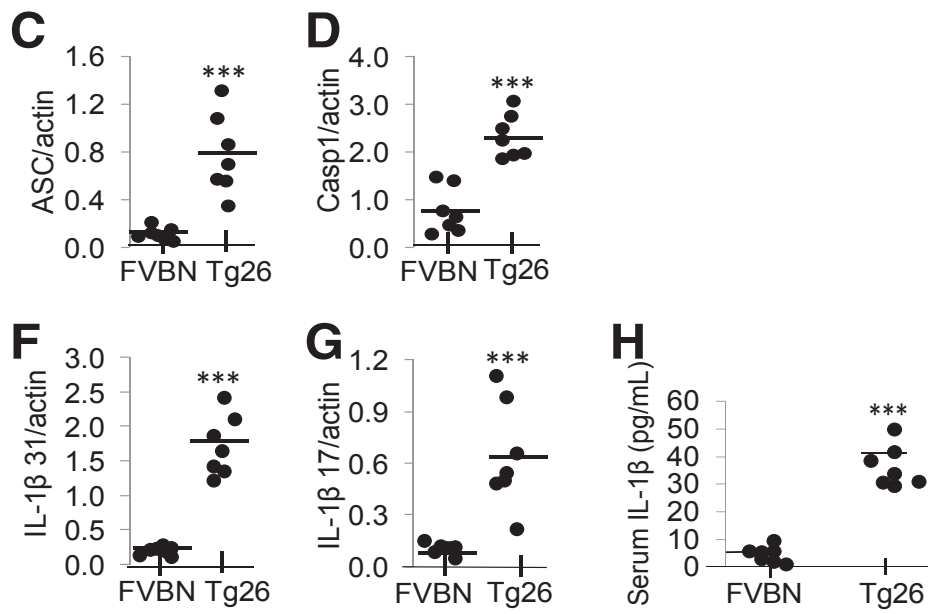

Figure 3 Renal tissues from Tg26 mice display enhanced inflammasome protein/cytokine markers. A: Cell lysates from renal tissues of FVBN and Tg26 mice were prepared. Proteins from each renal tissue were electrophoresed and transferred on to polyvinylidene difluoride membrane. B-G: Protein blots from renal

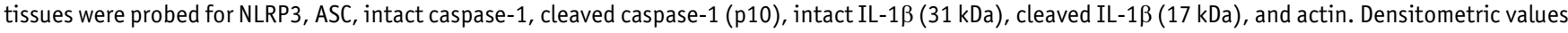
of cumulative data are shown as dot plots for NLRP3 (B), ASC (C), caspase-1 (D), caspase-1 p10 (E), and IL-1 31 kDa (F), and cleaved IL-1 $\beta 17$ kDa (G). H: Mature form of IL-1 $\beta$ concentration was quantitated in serum of FVBN and Tg26 mice with the use of enzyme-linked immunosorbent assay kit from R\&D Systems. Data are shown as dot plots in the form of mean values (horizontal bar) and scatter ( \pm SD). $n=7$ FVBN mice; $n=7$ Tg 26 mice. ${ }^{* * *} P<0.001$ versus respective FVBN. ASC, apoptosis-associated speck-like protein containing CARD and PYD domains; Casp1, caspase-1; NLRP, nucleotide oligomerization domain (Nod)-like receptor protein; Tg26, HIV-transgenic. 

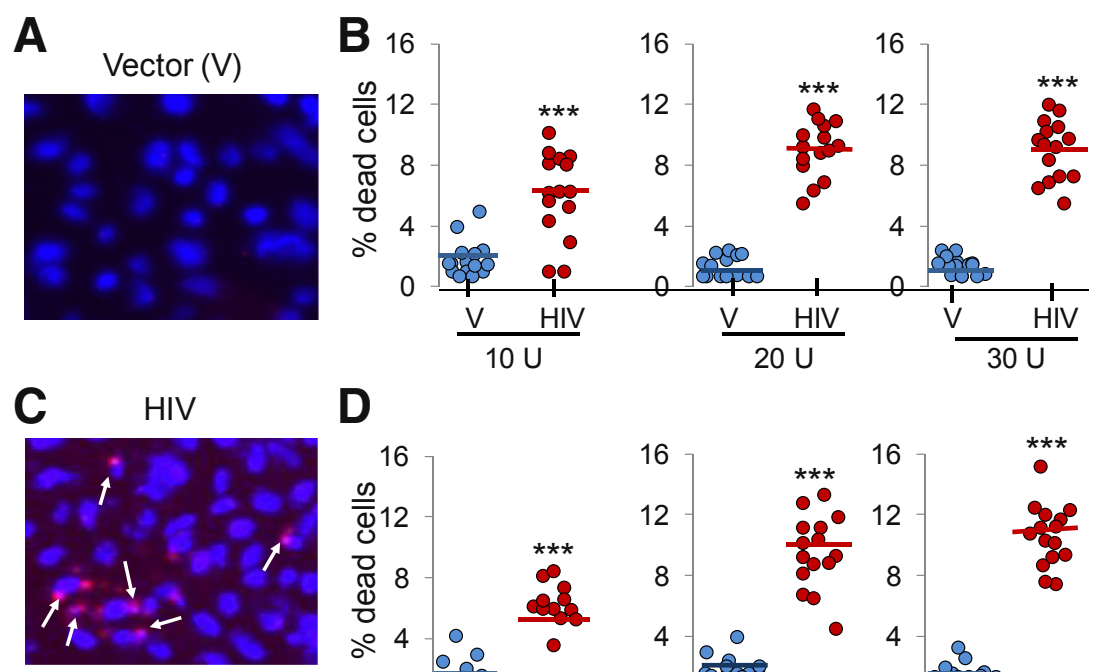

\section{D}
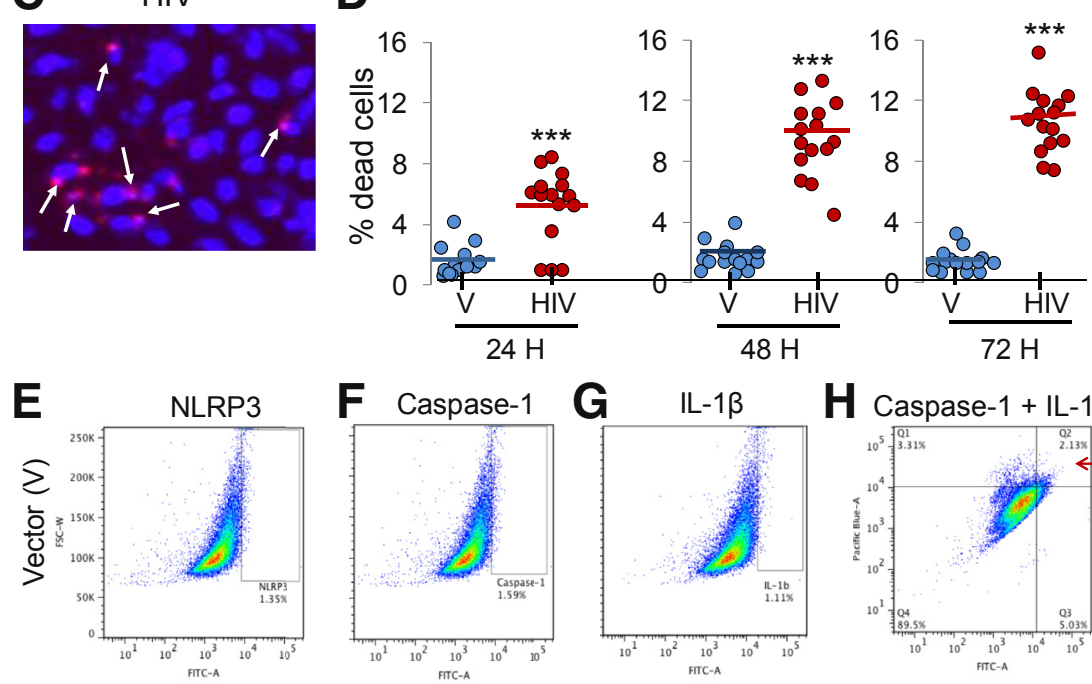

H
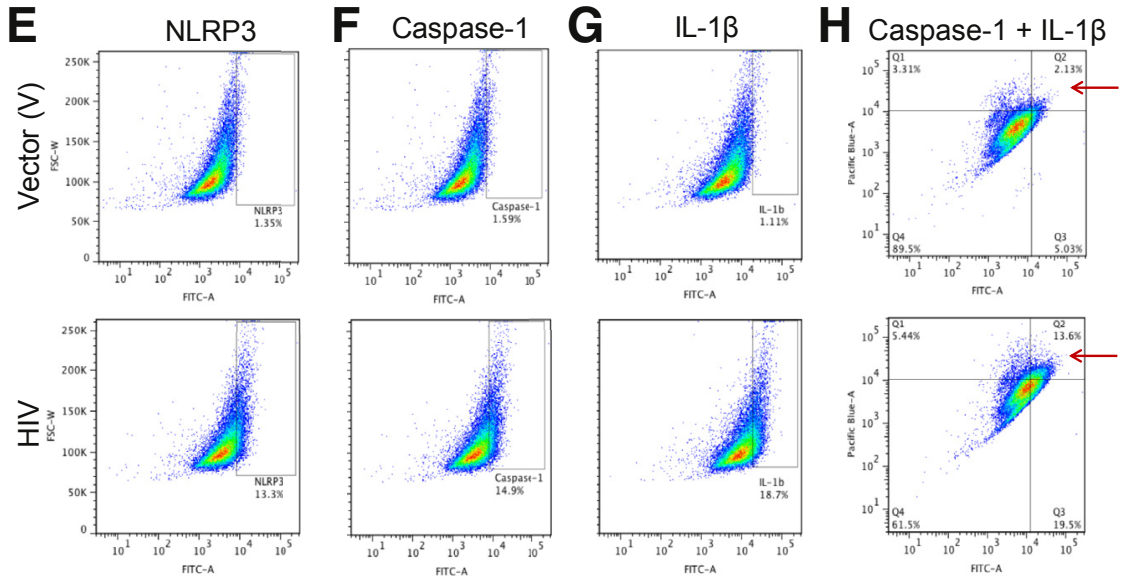

Figure 4 HIV induces cell death/pyroptosis in human podocytes. A and C: EV/HPs and HIV/HPs were incubated in media for 48 hours, followed by staining with Hoechst 33342 and propidium iodide, and morphologic assay of these cells was done under a fluorescence microscope. Representative microfluorographs of V/HPs (A) and HIV/HPs (C) are shown. Pyroptosed podocytes are indicated by white arrows. Human podocytes were transduced with variable concentration of $\mathrm{V}$ and HIV and then incubated in media for 48 hours. Subsequently, cells were stained and evaluated under a fluorescence microscope. B: Cumulative data are represented as dot plot. Human podocytes were transduced with $V$ and HIV and incubated in media for variable time periods (24, 48, and 72 hours). Subsequently, cells were subjected for pyroptosis assay. D: Cumulative data are represented as dot plot. V/HPs and HIV/HPs were incubated in media for 48 hours. E-G: Subsequently, cells were labeled for caspase-1 (FITC), IL-1 $\beta$ (FITC), and co-labeled for caspase- 1 (pacific blue) + IL-1 $\beta$ (FITC). Labeled cells were quantified by fluorescence-activated cell sorting analysis, data were analyzed by FlowJo (FlowJo, Ashland, OR). Representative scatter plots are shown. HIV/ HPs show 10-fold higher expression of NLRP3 (E), 9.4-fold higher expression of caspase-1 (F), and 16-fold higher expression of IL-1 $1 \beta$ (G). H: Colabeled HIV/HPs ( $y$ axis shows caspase- $1, x$ axis shows IL-1 $\beta$ expression) in quadrant Q2 (as indicated by red arrows) display sixfold higher expression than V/HPs. $n=15$ fields, five fields from each set of experiment (B and $\mathbf{D}$ ); ${ }^{* * *} P<0.001$ versus respective V. FITC, fluorescein isothiocyanate; HP, HIV expression by podocyte; NLRP, nucleotide oligomerization domain (Nod)-like receptor protein; V, vector.
HIV Induces Pyroptosis and Activates NLRP3 Inflammasome Complex Proteins in Human Podocytes

To assess HIV-induced cell death/pyroptosis, human podocytes were incubated with V or HIV for 48 hours, followed by staining with Hoechst 33342 and PI and examined under fluorescence microscope. Podocytes with small or fragmented nuclei stained pink were counted as pyroptosed cells. Figure 4, A and B, shows representative microfluorographs of V/HPs and HIV/HPs, respectively. To determine dose response, HPs were transduced at different concentrations of V or HIV and then stained for morphologic assay for pyroptosis. Cumulative data $(n=3$, five random fields from each set of experiment) are shown as dot plot (Figure 4C). On the basis of these data it appears that HIV induces cell death/pyroptosis in a dosedependent manner; however, the effect of HIV remained stable at $20 \mathrm{U}$.

To assess time course kinetics, human podocytes were transduced with V or HIV and incubated for 24,48 , or 72 hours. Subsequently, cells were subjected for pyroptosis assay. Cumulative data $(n=3)$ are shown as dot plot
(Figure 4D). HIV enhanced podocytes pyroptosis in a timedependent manner, peaking at 48 hours.

To quantify the percentage of podocyte display active inflammasome in HIV milieu, V/HPs and HIV/HPs were labeled for caspase-1, IL-1 $\beta$, or caspase- $1+$ IL- $1 \beta$ together. Labeled cells were quantified by fluorescence-activated cell sorting analysis. HIV/HPs displayed 10-fold higher NLRP3 expression (Figure 4E), 9.4-fold higher caspase-1 expression (Figure $4 \mathrm{~F}$ ), and 16-fold higher IL-1 $\beta$ expression (Figure $4 \mathrm{G}$ ) than V/HPs. Thirteen percent of HIV/HPs was positive for both casapse-1 and IL-1 $\beta$ (double-stained podocytes in quadrant Q2, indicated by red arrow), whereas V/HPs showed only $2.1 \%$ positivity (Figure $4 \mathrm{H}$ ). Taken together, the data strongly suggest that HIV activates the NLRP3 inflammasome complex in human podocytes.

\section{HIV Activates NLRP3 Inflammasome in Human Podocytes}

To determine a potential nonspecific effect of $\mathrm{V}$ on human podocyte NLRP3 inflammasome complex formation, blots of control and V/HPs were probed for caspase-1 expression, and the same blots were stripped and re-probed for 

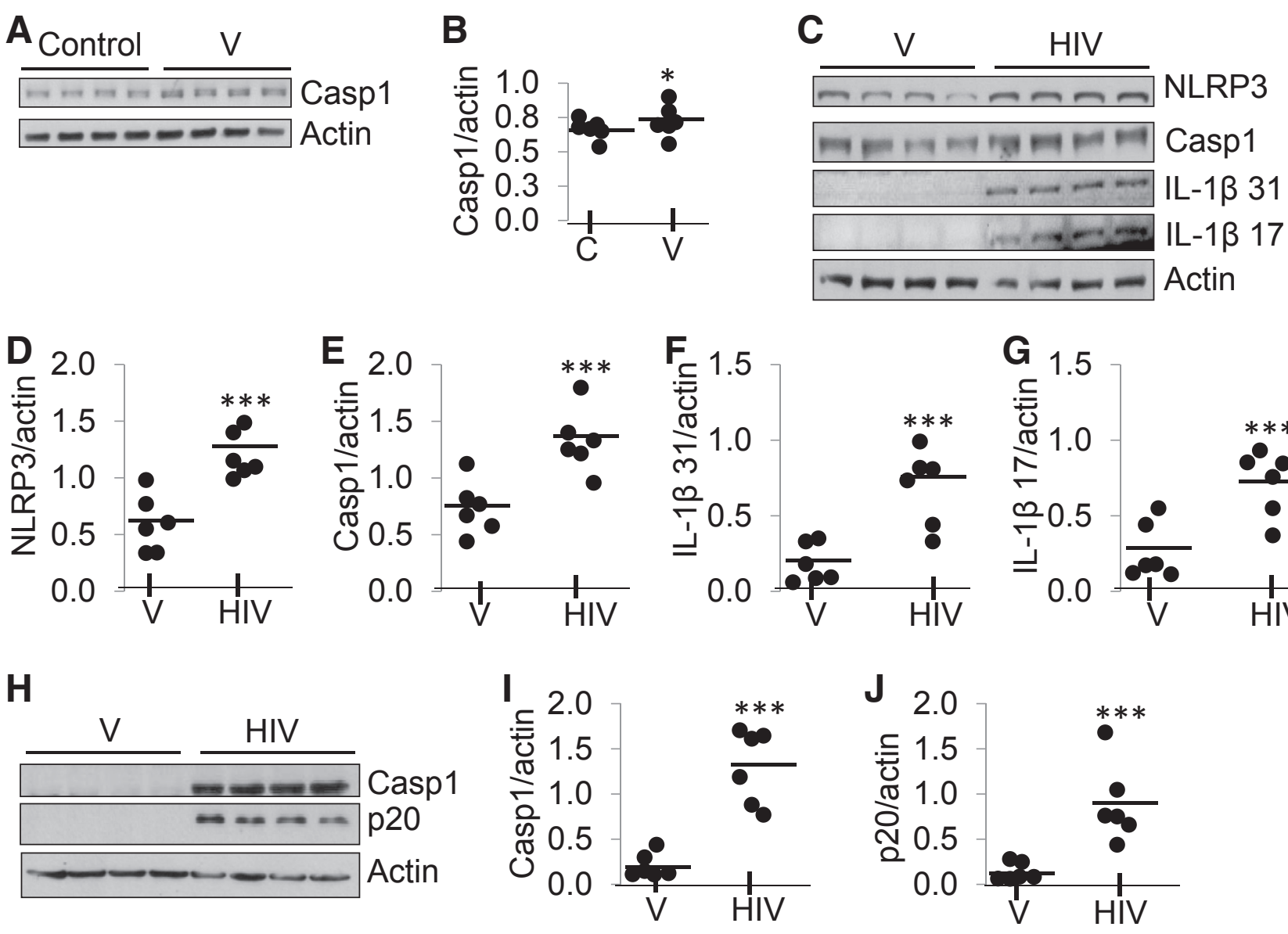

Figure 5 HIV activates NLRP3 inflammasome in podocytes. A: Protein blots of control and V/HPs were probed for caspase-1 expression, and the same blots were stripped and re-probed for actin. Representative gels are displayed. B: Densitometric data of caspase-1 expression (control versus V/HPs) are shown as dot plot. No difference was found between control and V/HPs in NLRP3 expression. C: Protein blots of EV/HPs and HIV/HPs were probed for NLRP3, Casp1

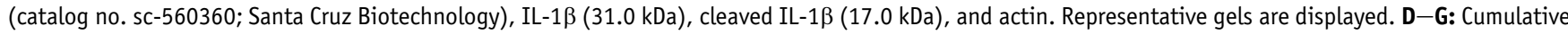

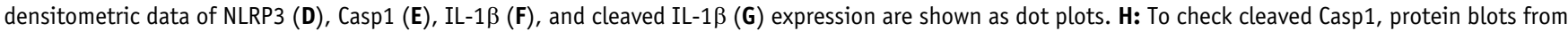
thee different sets of V/HPs and HIV/HPs were probed with Casp1 antibody (catalog no. 4199; cleaved Casp1 no. Asp297/D57A2; Cell Signaling) and reprobed for actin. I and J: Representative gels are displayed. Cumulative densitometric data (Casp1, I; p20, J) are shown as dot plot. Data are expressed as means (horizontal bar) $\pm \mathrm{SD}$ (scatter). $n=3(\mathbf{A}, \mathbf{C}$, and $\mathbf{H}) .{ }^{*} P<0.05$ versus control; ${ }^{* *} P<0.001$ versus HIV. C, control; Casp1, caspase-1; HP, HIV expression by podocyte; NLRP, nucleotide oligomerization domain (Nod)-like receptor protein; $V$, vector.

actin $(n=3)$. Representative gels are shown in Figure 5A. Densitometry data of caspase-1 expression (control versus $\mathrm{V}$ ) are shown as dot plot (means $\pm \mathrm{SD}$ ) (Figure 5B). No difference was found in caspase-1 expression in control and $\mathrm{V}$, suggesting that $\mathrm{V}$ can be used as an appropriate control. In subsequent experiments we used $\mathrm{V}$ as control.

Protein blots of V/HPs and HIV/HPs $(n=3)$ were probed for NLRP3, caspase-1 (Santa Cruz Biotechnology antibody), total IL-1 $\beta$ (31 kDa), cleaved (mature) IL-1 $\beta$ $(17 \mathrm{kDa})$, and actin. Representative gels from one set of experiments are shown (Figure 5C). Densitometric data revealed that NLRP3 expression was twofold higher in HIV/HPs (Figure 5D). Caspase-1 expression was also higher in HIV/HPs (Figure 5E). Expression of IL-1 $\beta$ (31 kDa) was twofold to threefold higher in HIV/HPs than in V/HPs (Figure 5F). Expression of cleaved IL-1 $\beta(17 \mathrm{kDa})$ was twofold higher in HIV/HPs than in V/HPs (Figure 5G).
To confirm cleavage of caspase-1, blot was probed for both intact and cleaved caspase 1 (Figure 5H). Densitometric data show that caspase-1 expression was 8- to 10-fold higher in HIV/HPs than in V/HPs (Figure 5I). Cleaved product p20 expression of caspase-1 was significantly upregulated in HIV/HPs (Figure 5J). Caspase-1 expression in Figure 5, $\mathrm{C}$ and $\mathrm{H}$, was probed with caspase- 1 antibodies with different specificity from two different suppliers (Santa Cruz Biotechnology and Cell Signaling).

Caspase-1 Inhibitor Attenuates HIV-Induced Caspase-1, Cleaved Caspase-1 p20, and IL-1 $\beta$ Expression in Podocytes To establish a causal relation between HIV and the activation of NLRP3 inflammasome protein complexes, V/HPs and HIV/HPs were incubated in the presence or absence of 5 $\mu \mathrm{mol} / \mathrm{L}$ caspase- 1 inhibitor for 48 hours $(n=3)$. Cell lysates were prepared, and protein blots were probed for caspase-1, IL-1 $\beta$, and actin. Representative gels are 

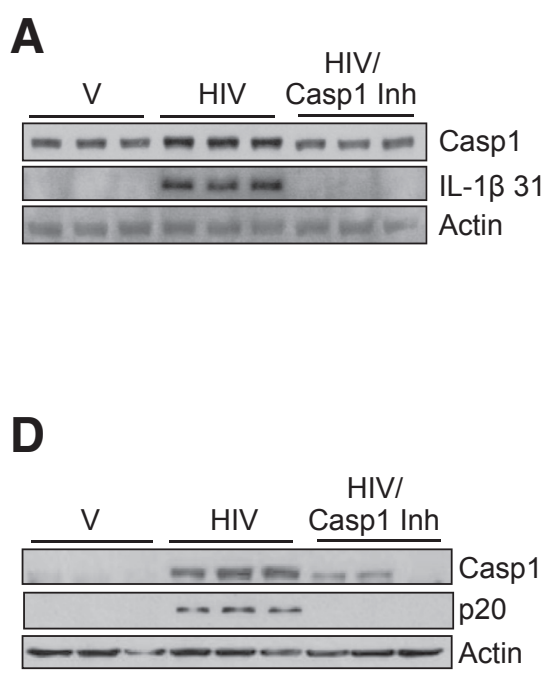
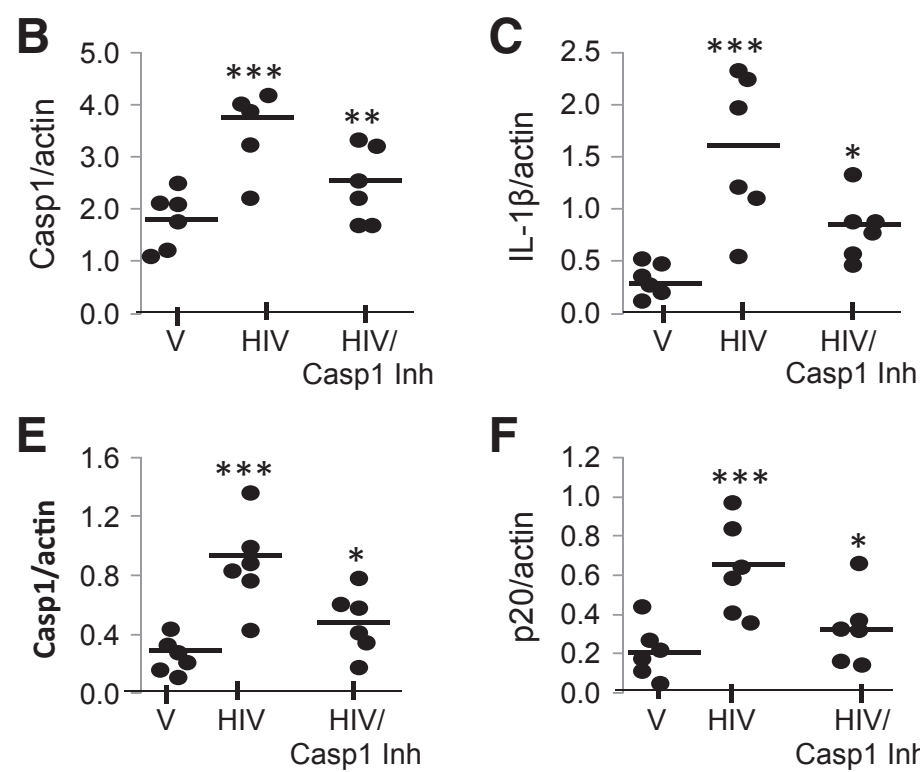

F

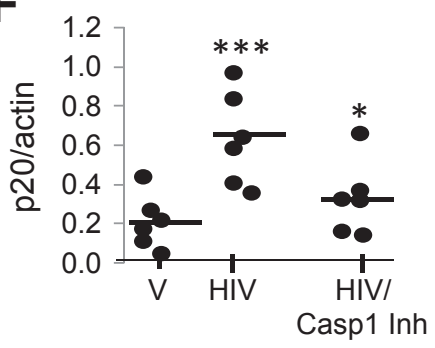

Figure 6 Casp1Inh reduces the activation of HIV-induced inflammasome in podocytes. V/HPs and HIV/HPs in the presence of absence of $5 \mu$ mol/L Casp1Inhfor 48 hours $(n=3$ ). Cell lysates were prepared and protein blots were probed for Casp1 (catalog no. sc-560360; Santa Cruz Biotechnology). A: The same blot was stripped and re-probed for IL-1 $\beta$ and actin. Representative gels are displayed. B: Induction of Casp1 expression in response to HIV and inhibition with Casp1Inhis represented as dot plot. C: Processing of IL-1 $\beta$ in response with HIV and inhibition in the presence of Casp1Inhis represented as dot plot. D: To analyze cleaved Casp1 p20, protein blots of samples treated with V, HIV, and HIV Casp1Inh were probed with Casp1 antibody (catalog no. 4199; cleaved Casp1 Asp297/D57A2; Cell Signaling). Representative gels are displayed. E and F: Cumulative densitometric data pertaining to intact Casp1expression (E) and cleaved Casp1 (F) are shown as dot plots. Data are expressed as means (horizontal bar) \pm SD (scatter). $n=3$. ${ }^{*} P<0.05$ versus respective HIV; ${ }^{* \star} P<0.01$ versus respective HIV; ${ }^{* *} P<0.001$ versus V. Casp1, caspase-1; Casp1Inh, caspase-1 inhibitor; HP, HIV expression by podocyte; $V$, vector.

displayed (Figure 6A). Cumulative data (caspase-1) are expressed as dot plot (Figure 6B). HIV/HPs displayed enhanced caspase-1 expression, but this effect of HIV was inhibited by a caspase-1 inhibitor. Similarly, HIV enhanced podocyte expression of IL-1 $\beta(31 \mathrm{kDa})$, but this effect of HIV was attenuated by a caspase- 1 inhibitor. Cumulative data as dot plot are shown in Figure 6C. These observations confirm the role of HIV in the activation of inflammasomes in human podocytes.

To confirm cleaved caspase- 1 in response to HIV, V and HIV/HPs were incubated in the presence or absence of caspase-1 inhibitor $(n=3)$. Protein blots were probed for intact and cleaved (p20) caspase-1. Representative gels are displayed in Figure 6D. Cumulative data are shown as dot plots (Figure 6, E and F). These findings confirmed that HIV induced cleavage of caspase-1 in podocytes, and this effect of HIV was inhibited by a caspase-1 inhibitor. The caspase-1 expression in Figure 6, A and D, were probed with caspase 1 antibodies having different specificity supplied by two separate vendors (Santa Cruz Biotechnology and Cell Signaling).
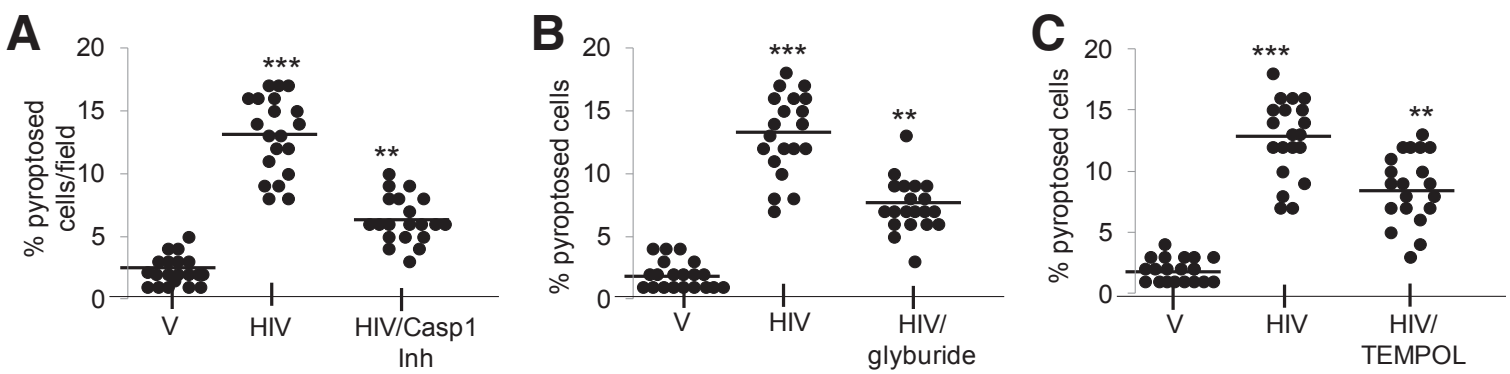

Figure 7 Caspase-1 inhibitor, glyburide (NLRP3 inhibitor), and Tempol reduce induced pyroptosis by HIV in human podocytes. A: Human podocytes were incubated with $V$ and HIV in media that contained either buffer or $5 \mu \mathrm{mol} / \mathrm{L}$ caspase-1 inhibitor for 48 hours, followed by morphologic assay for pyroptosis. Cumulative data are shown as dot plot. B: V/HPs and HIV/HPs were incubated with V and HIV in media that contained either buffer or 200 $\mu \mathrm{mol} / \mathrm{L}$ glyburide for 48 hours, followed by morphologic assay for pyroptosis. Cumulative data are shown as dot plot. C: V/HPs and HIV/HPs in media that contain either buffer or $10 \mu \mathrm{mol} / \mathrm{L}$ Tempol for 48 hours, followed by morphologic assay for pyroptosis. Cumulative data are shown in a dot plot. Each experiment was performed three times in duplicates. Data are expressed as means (horizontal bar) \pm SD (scatter). $n=3 . * * P<0.01$ versus HIV, ${ }^{* * * P}<0.001$ versus V. Casp1Inh, caspase-1 inhibitor; HP, HIV expression by podocyte; NLRP, nucleotide oligomerization domain (Nod)-like receptor protein; $V$, vector. 
Caspase-1 Inhibitor, Glyburide, and Tempol Reduces HIV-Induced Pyroptosis/Cell Death in Human Podocytes

To determine the role of caspase-1 inhibitor on cell death/ pyroptosis, human podocytes were incubated with $\mathrm{V}$ and HIV in media that contained either vehicle control or 5 $\mu \mathrm{mol} / \mathrm{L}$ caspase- 1 inhibitor for 48 hours, followed by morphologic assay for pyroptosis. The enhanced pyroptotic effect of HIV in podocytes was partially inhibited by caspase-1 inhibitor (Figure 7A).

To evaluate the role of potassium efflux (glyburideNLRP3 inhibitor), human podocytes were incubated with $\mathrm{V}$ and HIV in media that contained either vehicle control or $200 \mu \mathrm{mol} / \mathrm{L}$ glyburide for 48 hours, followed by morphologic assay for pyroptosis. Glyburide partially inhibited HIV-induced pyroptosis (approximately 50\%) in podocytes. These findings suggest that potassium efflux partly contributes to HIV-induced pyroptosis (Figure 7B).

To determine the role of oxidative stress, $\mathrm{V}$ and HIV were incubated in media that contained either buffer or $10 \mu \mathrm{mol} / \mathrm{L}$ Tempol for 48 hours, followed by morphologic assay for pyroptosis. HIV increased pyroptosis more than twofold in podocytes (Figure 7C); however, this effect of HIV was partially inhibited (50\%) by Tempol. These findings indicate that oxidative stress partly contributes to HIV-induced podocyte pyroptosis.

\section{Discussion}

In the present study podocytes in renal cortices of $\operatorname{Tg} 26$ mice demonstrated induction of NLRP3 multiprotein complex formation by displaying augmented expression of NLRP3, ASC, and caspase-1, and IL-1 $\beta$. Enhanced expression of IL-1 $\beta$ and active caspase- 1 in $\mathrm{Tg} 26$ mice further confirmed the activation of NLRP3 inflammasome protein complexes. Renal tissues of $\mathrm{Tg} 26$ mice not only displayed enhanced mRNA expression but also showed protein expression of molecules involved in NLRP3 inflammasome complexes. Podocyte HIV infection led to the expression of NLRP3 and caspase-1, establishing a causal relation between HIV infection and podocyte NLRP3 inflammasome complex formation. Because caspase-1 inhibitor attenuated HIV-mediated podocyte caspase-1 and IL-1 $\beta$ expression, it further confirms the role of HIV in podocyte inflammasome formation. The caspase-1 inhibitor not only attenuated podocyte expression of IL-1 $\beta$ but also provided protection against pyroptosis, suggesting that HIV induced podocyte phenotype was mediated by NLRP3 inflammasome complexes. Interestingly, HIVinduced podocyte pyroptosis could be partially inhibited by Tempol (a superoxide dismutase mimetic agent) and by glyburide (an inhibitor of potassium efflux or NLRP3 protein). These findings indicate that generation of reactive oxygen species and potassium efflux contributed to podocyte pyroptosis in HIV milieu.
Oxidative stress was reported to be contributing to the progression of HIV disease. ${ }^{25,26}$ Molecules consumed during the process of oxidative stress such as glutathione and antioxidants, including ascorbic acid, tocopherols, and selenium, are frequently lower in patients with HIV-1 infection. ${ }^{27-31} \mathrm{HIV}$-infected patients were also reported to display higher concentrations of serum markers of oxidative stress such as malondialdehyde and hydroperoxides, and oxygen consumption rates, which increase the oxygen load. ${ }^{32-35}$ Oxidative stress also contributes to viral replication, ${ }^{36,37}$ increases the inflammatory immune response, ${ }^{38}$ and accelerates the loss of immune function of the host. ${ }^{20}$ In a report, oxidative stress down-regulated vitamin D receptors in kidney cells and induced generation of renin and activation of renin angiotensin system in kidney cells in the HIV milieu. ${ }^{39}$ Induction of inflammasome formation in the HIV milieu adds a new paradigm to HIV's arsenal in addition to existing reported multiple subversion strategies. ${ }^{5}$ Recently, it was reported that diabetic kidney lesions were associated with NLRP3 inflammasome formation and that mito-tempol (a mitochondrial SOD mimetic agent) provided protection against the formation of inflammasomes and the development and progression of renal lesions. ${ }^{40}$ Similarly, in the present study, Tempol provided partial protection against HIV-induced podocyte pyroptosis.

Most proteinuric diseases, including HIVAN, are associated with podocytopathies (altered podocyte phenotypereduction in number and effacement of foot processes). ${ }^{1,41}$ Lysosomal cysteine protease cathepsin L (CTSL) leakage was incriminated for the loss of podocytes in these podocytopathies. ${ }^{23,42}$ Reactive oxygen species were reported to promote lysosomal leak of CTSL in adverse milieus. ${ }^{43}$ Because cathepsins are functional at neutral $\mathrm{pH}$, they carry the potential to induce cellular injury by cleavage of nuclear and cytoplasmic factors. ${ }^{44}$ We previously demonstrated that HIV-induced reactive oxygen species generation was associated with increased lysosomal membrane permeabilization and enhanced cytosolic accumulation of CTSL and associated reorganization of actin filaments in podocytes. ${ }^{45}$ This is consistent with the observations of other investigators in other models of chronic kidney diseases. ${ }^{46,47}$ Because CTSL leak is an inducer of inflammasome formation, it is likely that HIV-induced cytosolic leak of CTSL would have contributed to pyroptosis in the present study. Therefore, it would be worth investigating the role of CTSL in HIV-induced podocyte pyroptosis in future studies.

The renin angiotensin system was shown to play a critical role in the development and progression of HIVAN. ${ }^{12,42,48}$ Infusion of Ang II enhanced progression of renal lesions in an experimental mouse model of HIVAN. ${ }^{49}$ Conversely, blockade and inhibition of Ang II production slowed down HIVAN progression both in humans and in experimental animal models. ${ }^{50,51}$ Similarly, enhanced renin production accelerated progression of renal lesions, whereas inhibition 
of renin attenuated progression of renal lesions in HIVAN mice. ${ }^{52} \mathrm{HIV}$ was reported to stimulate production of Ang II in podocytes. ${ }^{45}$ On that account, Ang II-mediated reactive oxygen species generation and TGF- $\beta$ production may be contributing to podocyte injury in HIVAN. ${ }^{42}$ Because IL-1 $\beta$ stimulates TGF- $\beta$ generation within kidney cells, ${ }^{53}$ we speculate that the inflammasome may be a precursor of the profibrotic milieu in HIVAN. In addition, Ang II was shown to contribute to podocyte CTSL expression in the HIV milieu. ${ }^{39}$ Thus, it appears that in podocytopathies associated with proteinuric diseases, inflammasomes may be playing a dual role: proinflammatory and profibrotic milieu.

In conclusion, HIV promotes NLRP3 inflammasome protein complex formation in HIVAN. The present study highlights involved molecular mechanism in HIV-induced pyroptosis in podocytes and provides a basis to support the use of new therapeutic targets for HIVAN in future studies.

\section{Acknowledgments}

We thank Prof. Paul E. Klotman (Baylor College of Medicine, Houston, TX), Dr. Moin A. Saleem (University of Bristol, Southmead Hospital, Bristol, UK), and Dr. Didier Trono (Salk Institute, La Jolla, CA) for the breeding pairs to develop Tg26 colonies, LY $8+13$ cell line, and pCMV R8.91 and pMD.G plasmids, respectively.

\section{References}

1. Kriz W, Gretz N, Lemley KV: Progression of glomerular diseases: is the podocyte the culprit? Kidney Int 1998, 54:687-697

2. Li JJ, Kwak SJ, Jung DS, Kim JJ, Yoo TH, Ryu DR, Han SH, Choi HY, Lee JE, Moon SJ, Kim DK, Han DS, Kang SW: Podocyte biology in diabetic nephropathy. Kidney Int Suppl 2007, 106:S36-S42

3. Cassel SL, Joly S, Sutterwala FS: The NLRP3 inflammasome: a sensor of immune danger signals. Semin Immunol 2009, 21:194-198

4. Davis BK, Wen H, Ting JP: The inflammasome NLRs in immunity, inflammation, and associated diseases. Annu Rev Immunol 2011, 29: $707-735$

5. Kanneganti TD: Central roles of NLRs and inflammasomes in viral infection. Nat Rev Immunol 2010, 10:688-698

6. Kanneganti TD, Ozoren N, Body-Malapel M, Amer A, Park JH, Franchi L, Whitfield J, Barchet W, Colonna M, Vandenabeele P, Bertin J, Coyle A, Grant EP, Akira S, Nunez G: Bacterial RNA and small antiviral compounds activate caspase-1 through cryopyrin/Nalp3. Nature 2006, 440:233-236

7. Takeuchi O, Akira S: Pattern recognition receptors and inflammation. Cell 2010, 140:805-820

8. Barlan AU, Danthi P, Wiethoff CM: Lysosomal localization and mechanism of membrane penetration influence nonenveloped virus activation of the NLRP3 inflammasome. Virology 2011, 412: 306-314

9. Negash AA, Ramos HJ, Crochet N, Lau DT, Doehle B, Papic N, Delker DA, Jo J, Bertoletti A, Hagedorn CH, Gale M Jr: IL-1beta production through the NLRP3 inflammasome by hepatic macrophages links hepatitis $\mathrm{C}$ virus infection with liver inflammation and disease. PLoS Pathog 2013, 9:e1003330

10. Nour AM, Reichelt M, Ku CC, Ho MY, Heineman TC, Arvin AM: Varicella-zoster virus infection triggers formation of an interleukin-1 beta (IL-1beta)-processing inflammasome complex. J Biol Chem 2011, 286:17921-17933

11. Segovia J, Sabbah A, Mgbemena V, Tsai SY, Chang TH, Berton MT, Morris IR, Allen IC, Ting JP, Bose S: TLR2/MyD88/NF-kappaB pathway, reactive oxygen HIV-1 infection activates NLRP3inflammasome 12 species, potassium efflux activates NLRP3/ASC inflammasome during respiratory syncytial virus infection. PLoS One 2012, 7:e29695

12. Kumar D, Salhan D, Magoon S, Torri DD, Sayeneni S, Sagar A, Bandhlish A, Malhotra A, Chander PN, Singhal PC: Adverse host factors exacerbate occult HIV-associated nephropathy. Am J Pathol 2011, 179:1681-1692

13. Pohlers D, Brenmoehl J, Löffler I, Müller CK, Leipner C, SchultzeMosgau S, Stallmach A, Kinne RW, Wolf G: TGF-beta and fibrosis in different organs - molecular pathway imprints. Biochim Biophys Acta 2009, 1792:746-756

14. Yamamoto T, Noble NA, Miller DE, Gold LI, Hishida A, Nagase M, Cohen AH, Border WA: Increased levels of transforming growth factor-beta in HIV-associated nephropathy. Kidney Int 1999, 55:579-592

15. Berliner AR, Fine DM, Lucas GM, Rahman MH, Racusen LC, Scheel PJ, Atta MG: Observations on a cohort of HIV-infected patients undergoing native renal biopsy. Am J Nephrol 2008, 28:478-486

16. Friedman DJ, Kozlitina J, Genovese G, Jog P, Pollak MR: Populationbased risk assessment of APOL1 on renal disease. J Am Soc Nephrol 2011, 22:2098-2105

17. Kopp JB, Nelson GW, Sampath K, Johnson RC, Genovese G, An P, Friedman D, Briggs W, Dart R, Korbet S, Mokrzycki MH, Kimmel PL, Limou S, Ahuja TS, Berns JS, Fryc J, Simon EE, Smith MC, Trachtman H, Michel DM, Schelling JR, Vlahov D, Pollak M, Winkler CA: APOL1 genetic variants in focal segmental glomerulosclerosis and HIV-associated nephropathy. J Am Soc Nephrol 2011, 22:2129-2137

18. Suthanthiran M, Gerber LM, Schwartz JE, Sharma VK, Medeiros M, Marion R, Pickering TG, August P: Circulating transforming growth factor-beta1 levels and the risk for kidney disease in African Americans. Kidney Int 2009, 76:72-80

19. Pontillo A, Brandao LA, Guimaraes RL, Segat L, Athanasakis E, Crovella S: A 3'UTR SNP in NLRP3 gene is associated with susceptibility to HIV-1 infection. J Acquir Immune Defic Syndr 2010, $54: 236-240$

20. Pontillo A, Silva LT, Oshiro TM, Finazzo C, Crovella S, Duarte AJ: HIV-1 induces NALP3-inflammasome expression and interleukin1beta secretion in dendritic cells from healthy individuals but not from HIV-positive patients. AIDS 2012, 26:11-18

21. Doitsh G, Galloway NL, Geng X, Yang Z, Monroe KM, Zepeda O, Hunt PW, Hatano H, Sowinski S, Muñoz-Arias I, Greene WC: Cell death by pyroptosis drives CD4 T-cell depletion in HIV-1 infection. Nature 2014, 505:509-514

22. Husain M, Meggs LG, Vashistha H, Simoes S, Griffiths KO, Kumar D, Mikulak J, Mathieson PW, Saleem MA, Del Valle L, PinaOviedo S, Wang JY, Seshan SV, Malhotra A, Reiss K, Singhal PC: Inhibition of p66ShcA longevity gene rescues podocytes from HIV-1induced oxidative stress and apoptosis. J Biol Chem 2009, 284: 16648-16658

23. Saleem MA, O'Hare MJ, Reiser J, Coward RJ, Inward CD, Farren T, Xing CY, Ni L, Mathieson PW, Mundel P: A conditionally immortalized human podocyte cell line demonstrating nephrin and podocin expression. J Am Soc Nephrol 2002, 13:630-638

24. Miao EA, Rajan JV, Aderem A: Caspase-1-induced pyroptotic cell death. Immunol Rev 2011, 243:206-214

25. Pace GW, Leaf CD: The role of oxidative stress in HIV disease. Free Radic Biol Med 1995, 19:523-528

26. Stephensen CB, Marquis GS, Douglas SD, Wilson CM: Immune activation and oxidative damage in HIV-positive and HIVnegative adolescents. J Acquir Immune Defic Syndr 2005, 38: $180-190$ 
27. Eck HP, Stahl-Henning C, Hunsmann G, Droege W: Metabolic disorder as early consequence of simian immunodeficiency virus infection in rhesus macaques. Lancet 1991, 338:346-347

28. Buhl R, Jaffe HA, Holroyd KJ, Wells FB, Mastrangeli A, Saltini C, Cantin AM, Crystal RG: Systemic glutathione deficiency in symptomfree HIV-seropositive individuals. Lancet 1989, 2:1294-1298

29. Droge W: Cysteine and glutathione deficiency in AIDS patients: a rationale for the treatment with $\mathrm{N}$-acetyl-cysteine. Pharmacology 1993, 46:61-65

30. Dworkin BM: Selenium deficiency in HIV infection and the acquired deficiency syndrome (AIDS). Chem Biol Interact 1994, 91:181-186

31. Giorgi G, Michell L, Fiaschi AI, Dal Pra P, Bozzo M: Glutathione deficiency in human HIV infection. Pharmacol Res 1990, 22(Suppl 2):231

32. Favier A, Sappey C, Leclerc P, Faure P, Micoud M: Antioxidant status and lipid peroxidation in patients infected with HIV. Chem Biol Interact 1994, 91:165-180

33. Leff JA, Oppegard MA, Curiel TJ, Brown KS, Schooley RT, Rapine JE: Progressive increases in serum catalase activity in advancing human immunodeficiency virus infection. Free Radic Biol Med 1992, 13:143-149

34. Revillard JP, Vincent CM, Favier AE, Richard MJ, Zittoun M, Kazatchkine MD: Lipid peroxidation in human immunodeficiency virus infection. J Acquir Immune Defic Syndr 1992, 5:637-638

35. Sonnerberg A, Carlin G, Akerlund B, Jastrand C: Increased production of malondialdehyde in patients with HIV infection. Scand J Infect Dis 1988, 20:287-290

36. Nabel GE, Baltimore D: An inducible transcription factor activates expression of human immunodeficiency virus in T-cells. Nature 1987, 326:711-713

37. Staal FJT, Roederer M, Herzenberg LA: Intracellular thiols regulate activation of nuclear factor $\mathrm{kB}$ transcription factor. Cell 1988, 53: 211-217

38. Fidelus RK: The generation of oxygen radicals: a positive signal for lymphocyte activation. Cell Immunol 1988, 113:175-182

39. Salhan D, Husain M, Subrati A, Goyal R, Singh T, Rai $P$, Malhotra A, Singhal PC: HIV-induced kidney cell injury: role of ROS-induced downregulated vitamin D receptor. Am J Physiol Renal Physiol 2012, 303:F503-F514

40. Shahzad K, Bock F, Dong W, Wang H, Kopf S, Kohli S, Al-Dabet MM, Ranjan S, Wolter J, Wacker C, Biemann R, Stoyanov S, Reymann K, Söderkvist P, Groß O, Schwenger V, Pahernik S, Nawroth PP, Gröne HJ, Madhusudhan T, Isermann B: Nlrp3-inflammasome activation in non-myeloid-derived cells aggravates diabetic nephropathy. Kidney Int 2015, 87:74-84

41. Barisoni L, Kriz W, Mundel P, D’Agati V: The dysregulated podocyte phenotype: a novel concept in the pathogenesis of collapsing idiopathic focal segmental glomerulosclerosis and HIV-associated nephropathy. J Am Soc Nephrol 1999, 10:51-61
42. Rüster C, Wolf G: Renin-angiotensin-aldosterone system and progression of renal disease. J Am Soc Nephrol 2006, 17: 2985-2991

43. Chen QY, Shi JG, Yao QH, Jiao DM, Wang YY, Hu HZ, Wu YQ, Song J, Yan J, Wu LJ: Lysosomal membrane permeabilization is involved in curcumin-induced apoptosis of A549 lung carcinoma cells. Mol Cell Biochem 2012, 359:389-398

44. Repnik U, Stoka V, Turk V, Turk B: Lysosomes and lysosomal cathepsins in cell death. Biochim Biophys Acta 2012, 1824:22-33

45. Chandel N, Sharma B, Husain M, Salhan D, Singh T, Rai P, Mathieson PW, Saleem MA, Malhotra A, Singhgl PC: HIV compromises integrity of the podocyte actin cytoskeleton through downregulation of the vitamin D receptor. Am J Physiol Renal Physiol 2013, 304:F1347-F1357

46. Reiser J, Oh J, Shirato I, Asanuma K, Hug A, Mundel TM, Honey K, Ishidoh K, Kominami E, Kreidberg JA, Tomino Y, Mundel P: Podocyte migration during nephrotic syndrome requires a coordinated interplay between cathepsin L and alpha3 integrin. J Biol Chem 2004, 279:34827-34832

47. Sever S, Altintas MM, Nankoe SR, Möller CC, Ko D, Wei C, Henderson J, del Re EC, Hsing L, Erickson A, Cohen CD, Kretzler M, Kerjaschki D, Rudensky A, Nikolic B, Reiser J: Proteolytic processing of dynamin by cytoplasmic cathepsin $\mathrm{L}$ is a mechanism for proteinuric kidney disease. J Clin Invest 2007, 117: 2095-2104

48. Plagov A, Lan X, Rai P, Kumar D, Lederman R, Rehman S, Malhotra A, Ding G, Chander PN, Singhal PC: Modulation of renin angiotensin system predominantly alters sclerotic phenotype of glomeruli in HIVAN. Histol Histopathol 2014, 29: $1575-1581$

49. Ideura H, Hiromura K, Hiramatsu N, Shigehara T, Takeuchi S, Tomioka M, Sakairi T, Yamashita S, Maeshima A, Kaneko Y, Kuroiwa T, Kopp JB, Nojima Y: Angiotensin II provokes podocyte injury in murine model of HIV-associated nephropathy. Am J Physiol Renal Physiol 2007, 293:F1214-F1221

50. Bird JE, Durham SK, Giancarli MR, Gitliz PH, Pandya DG, Dambach DM, Mozes MM, Kopp JB: Captopril prevents nephropathy in HIV-transgenic mice. J Am Soc Nephrol 1998, 9: $1441-1447$

51. Burns GC, Paul SK, Toth IR, Sivak SL: Effect of angiotensinconverting enzyme inhibition in HIV-associated nephropathy. J Am Soc Nephrol 1997, 8:1140-1146

52. Kumar D, Plagov A, Yadav I, Torri DD, Sayeneni S, Sagar A, Rai P, Adabala M, Lederman R, Chandel N, Ding G, Malhotra A, Singhal PC: Inhibition of renin activity slows down the progression of HIV-associated nephropathy. Am J Physiol Renal Physiol 2012, 303:F711-F720

53. Luo DD, Fielding C, Phillips A, Fraser D: Interleukin-1 beta regulates proximal tubular cell transforming growth factor beta-1 signalling. Nephrol Dial Transplant 2009, 24:2655-2665 